\title{
Defense Mechanisms and Respiratory Parameters
}

\author{
Uwe Hentschel ${ }^{1}$, Thomas van Praag ${ }^{2}$, Manfred Kießling ${ }^{3}$ \\ ${ }^{1}$ Department of Psychology, University of Leiden, Leiden, The Netherlands; \\ ${ }^{2}$ Cope, Leiden, The Netherlands; \\ ${ }^{3}$ GPS, Mainz, Germany. \\ Email: hentsche@fsw.leidenuniv.nl \\ Received March 16 ${ }^{\text {th }}, 2011$; revised May 14 ${ }^{\text {th }}, 2011$; accepted June $11^{\text {th }}, 2011$.
}

\begin{abstract}
The purpose of the study was to look the relation of stress, respiration and gender to defense mechanisms. A questionnaire was used to measure Turning against Object, Projection and Reversal and showed a negative relation to stress, measured by a high-speed task at the PC, representing a cognitive task. Defense mechanisms showed also a negative relationship to the respiratory variables, Amplitude per minute and Time in. Steepness and Amplitude per minute showed a greater value for women. Pause at the end of inhalation, Time in and Frequency gave a greater value for men, who also showed more stress. Thus defense mechanisms can obviously help to prevent cognitive stress, with respiration they showed mixed results. Future research should especially pay more attention to the existing gender differences in respiration as well as in defense mechanisms.
\end{abstract}

Keywords: Defense Mechanisms, Respiratory Variables, Gender Differences, Optimal Scaling

\section{Introduction}

Defense mechanisms have been introduced as unconscious variables that can be chosen by the respondents according to their prevailing needs. In fact, they are trait variables that are not so easily changed. Vaillant (1977) especially has shown that they are pretty stable without any psychotherapeutic intervenetion and remain constant over more than 30 years. Kragh (1985; cf. also Smith \& Hentschel, 2004) has also found fairly stable patterns for defense mechanisms.

This report used questionnaire items to measure defense mechanisms by means of the 'Fragebogen zu Konfliktbewältigungsstrategien' (FKBS) [Conflict-Solving Strategies Inventory] (Hentschel, Kießling, \& Wiemers, 1998). The FKBS shows, among other results, relationships to pain (Egle et al., 1989), psychotherapeutic interventions (cf. Geiser, Imbierovicz, Conrad, Wegener, \& Liedtke, 2005; Liedtke, Künsebeck, \& Lempa, 1990), sleep disturbances (Hermann-Maurer et al., 1992), and dreams (Hentschel, Van der Voort, \& Davids, 2007). The FKBS has some projective components, in contrast to many other questionnaire items by its mode of presentation, like the Defense Mechanisms Inventory (DMI) (Gleser \& Ihilevich, 1969).

Breathing is a variable under unconscious as well as conscious control. People can easily shift from one to the other mode, but mostly, under normal circumstances, we do not pay attention to our respiration (Harver \& Lorig, 2000). The normal breathing cycle has 3 phases, which in the ideal case, have an equal length: inspiration, expiration and pause. Respiration consists mostly of situational aspects (Wientjes, 1993). The respiratory parameters are thus, to a greater extent, state variables.

Both measures - respiratory parameters as well as defensesusually show gender differences. For defenses, this difference has been avoided often by using only male respondents. Also we started our breathing research with a pure male sample (cf.
Van Praag, 1995) and then detected the gender differences.

The first author has together with his co-authors (Hentschel, Smith, \& Draguns, 2004) summarized many results on defense mechanisms as revealing differences in information processing, a link that also has been evident in respiration (Wientjes, Grossman, Gaillard, \& Defares, 1986).

Breathing variables can be constructed from the main respiratory cycle, with almost no limit in number, if one admits higher correlations of them. The main difference is that defenses are trait variables and breathing has to be regarded mainly as a state.

\section{Method}

\section{Sample}

The whole sample comprised hundred and three persons, 50 males and 53 females, in the age range of 18 to 55 years. The age range was equal for the 2 groups. They were students or members of a Dutch air company. All were volunteers and received the test results and were invited to a cup of coffee or tea.

\section{Instruments}

To measure defense mechanisms we used the FKBS [Conflict-Solving Strategies Inventory], which is mainly documented in the German manual (cf. Hentschel et al, 1998). A native speaker made the translation into Dutch. Although there is a large database, there are no official norms for the Dutch version, thus the reliability values in Table 1 come from the German manual. The lack of norms has however no influence on our results, in which norm values were not used. All FKBS variables (15 in total) were used in the beginning and exclusions were made later on the basis of the ANOVA results (see Method of Analysis section). The FKBS has good reliabilities (all Cronbach's Alphas equal or are above .78 in the German 
standardization sample) and knows 5 defenses (cf. Hentschel et al., 1998). The FKBS has been developed basically in analogy to the DMI (Gleser \& Ihilevich, 1969), but has fewer defenses, only 2 modes of answering (feeling and doing) and mainly other stories. Three mechanisms of defense were included in the present analysis (TAO, Turning against Object; PRO, Projection; REV, Reversal). The defense mechanisms in the FKBS can be grouped according to the ways of responding to the threat (feeling, doing, and total scores). The defenses included in this report and the method of response, are given in Table 1.

We have measured respiration by two belts, one around the chest and one around the stomach. As there were too many respiratory variables in the beginning, a selection had to be made there as well. We have used 2 methods for doing this (cf. Method of Analysis section). The respiration parameters used, are summarized in Table 2.

Stress was imposed by a speeded multiple decision task, presented to the respondents on a personal computer. The task consisted of reacting as soon as possible to 4 different colors and reacting at the same time to high and low tones presented via earphones. The stress task is described in more detail in Table 4.

\section{Procedure}

The participants were administered the FKBS. They were fitted with 2 belts to measure the breathing variables. Then the timed decision task was administered, measuring the breathing variables continuously. Their sex was registered; their age was limited by admission to the tasks. All ordinal groups were formed by the grouping program of SPSS (1990) for their use in the further analysis.

\section{Method of Analysis}

We shall present our results mainly by means of a nonlinear canonical correlation analysis; i.e. OVERALS (SPSS, 1990). In this program, the scaling levels of the variables included can be chosen (defenses, respiration and the stress variables were taken as ordinal, gender as single nominal). The program gives a Fit value, i.e. how much the results correspond with the data at hand; it has also the advantage that the results can be presented in form of a graphical model. For OVERALS we have used a grouping of the cases with different numbers of groups (cf. Tables 1 and 2 and the Instruments section) and limited the output to two dimensions.

Fit and Loss are the only estimates one gets, i.e. OVERALS does not give a real test result for the included variables. Both values provide only a comparison of the weighted sum of the included variables with the object scores, which in our case are the values of the respondents. The indications are in general, comparable to other statistical procedures, lower with a greater number of the included variables. For further details of the method see Van der Burg, de Leeuw and Verdegaal (1988) and Bijleveld and Van der Burg (1998).

Given the problematic gender differences, among other things, we have applied many ANOVA's. Those analyses shall however not be reported in detail as they only were used to select the most important variables by the post hoc results of the ANOVA's. For the ANOVA analyses we have divided the whole sample in almost equal parts into an analysis and a validation group. Only variables that have shown significant results in both analyses, in the analysis as well as in the validation group, were included in OVERALS. We thus can lean with our results also on traditional p-values.

Exclusions of the respiratory variables were based on the ANOVA results and too high inter-correlations among them. As the remaining respiratory parameters still were not completely independent, a Pearson correlation analysis of the used ones (Minute ventilation, Steepness, Frequency, Pause at the end of inhalation, Time in) is also presented in Table 3 (see the Results section).

We ended up finally with 3 defense mechanisms and 5 respiratory variables.

\section{Results}

Table 1 gives a description and an overview of the abbreviations used for the defenses, and the number of groups of the respondents. Table 2 presents a description for the respiratory variables and an overview of the abbreviations used, together with the number of groups of the respondents. Table 3 gives the inter-correlations of the respiratory variables. In Table 4 the stress induction is presented. Figure 1 presents the graphical summary of OVERALS with 2 dimensions. As far as it concerns variables with an ordinal level, projected centroids are given. For variables with a nominal scale level, centroids are used. The arrows always represent the highest value of the respective variable. The lengths of the respective lines represent the importance of a relationship, i.e. a vector. The Fit of the OVERALS solution (1.02) has to be evaluated as pretty good, and the Loss is accordingly 0.98 . If the solution would be in perfect agreement with the data, the maximum value would equal 2.0 (the number of dimensions in the OVERALS solution).

It is remarkable that a high level of defense mechanisms (TAO, PRO, REV) has a negative relationship to cognitive stress (high speed of a multiple decision task on the PC). For

Table 1.

The defense mechanisms used in the analysis.

\begin{tabular}{ccccc}
\hline Defense mechanisms & Abbreviation in Figure 1 & Form of response used & Meaning or example & Cronbach's $\alpha$ \\
Reversal & REV & Feeling & $\begin{array}{c}\text { Thinking that the frustrator is a } \\
\text { nice person }\end{array}$ \\
Turning against object & TAO & Doing & Smashing a door \\
Projection & PRO & Feeling & $\begin{array}{c}\text { Thinking that the frustrator has } \\
\text { done it with vexatious motives }\end{array}$ \\
\hline
\end{tabular}


Table 2.

The respiratory variables in the OVERALS solution.

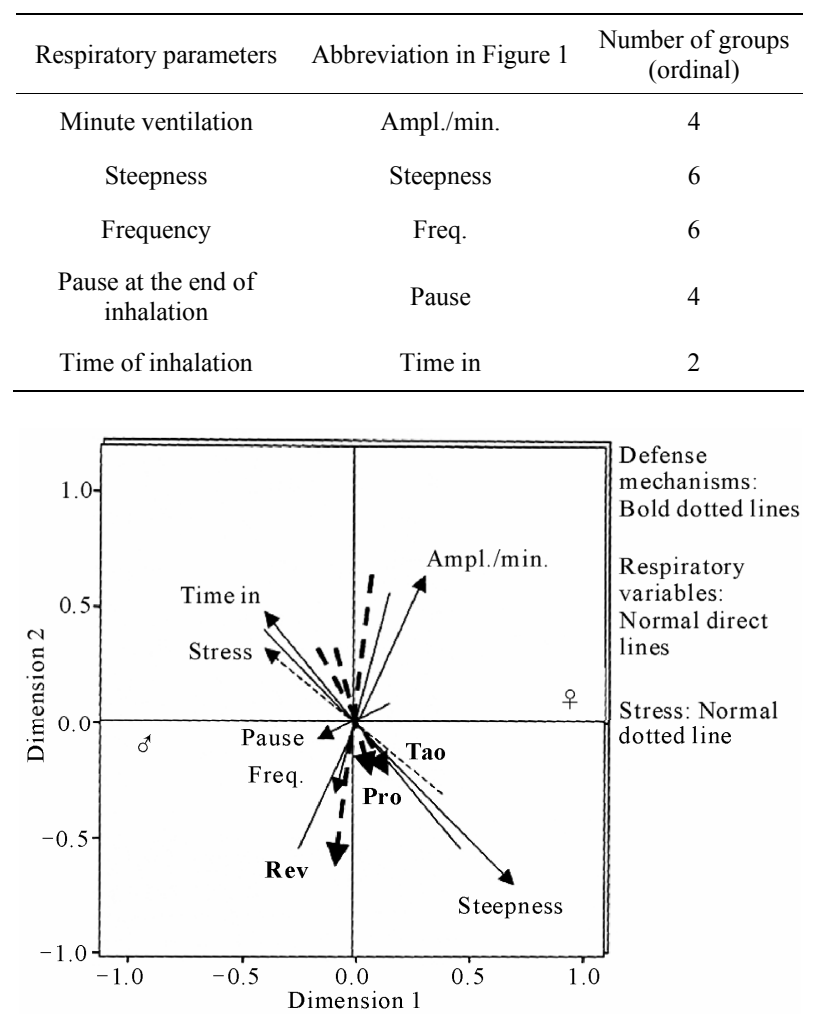

Figure 1.

The OVERALS solution for defenses, respiratory parameters, stress and the gender of the respondents.

the respiration parameters the results are however mixed. Minute volume (Ampl./min.) and Time in are in contrary direction to the defenses, whereas Pause is in-between, Steepness and Frequency go together with the defense mechanisms. Thus these respiration variables show a higher non-linear relationship to the defense mechanisms. Male respondents seem to have experienced more stress than the females. They react more with respiration also (higher values of Time in, Pause and Frequency). The females show higher values of Minute ventilation (Ampl./min.) and Steepness.

\section{Discussion}

A combination of state and trait variables seems especially promising, if the trait variables also show some change, like defense mechanisms do with psychotherapy for example. With regard to defense mechanisms, questionnaires and other methods of registering them usually do not correlate to a higher degree, which is basically a theoretical problem. This holds also true for the FKBS with at least some projective aspects. The relationship to different outside criteria may be however nevertheless satisfactory. This has to be cross-validated for respiration, of course. It is relatively new that respiration is regarded as an information-processing variable. This should open up the relationship of respiration to more personality variables that have some connection with information processing.

Usually only the chest changes of air in the lungs are registered for respiration, but for the relationship with emotions and defense mechanisms it is better to use two belts: A chest belt and a stomach belt, or any other measures, are thus recommended.

In the in the beginning of our research, we had high hopes for differentiation between chest and stomach respiration. Adding females to the sample ended most of these hopes. More research seems recommended here.

It is very unfortunate that speech and respiration cannot be measured together, i.e. that all tasks that are to be studied in

Table 3.

Pearson correlations of the respiratory parameters.

\begin{tabular}{|c|c|c|c|c|}
\hline & Minute ventil. & Steepness & Freq. & Pause in \\
\hline Minute ventilation (Amplitude/min.: chest and stomach) & -- & -- & -- & -- \\
\hline Steepness (at the beginning of exhaling; low values $=$ high steepness) & $-.66^{* *}$ & -- & -- & -- \\
\hline Frequency (Freq.: $1 /$ (cycle length) $\times 60$ & .13 & $.22 *$ & -- & -- \\
\hline Pause in (pause at the end of inhalation) & $-.55^{* *}$ & $.60^{* *}$ & $.29 * *$ & -- \\
\hline Time in ( $\%$ of inhalation of the whole respiration cycle $)$ & $-.29 * *$ & .11 & $-.28 * *$ & $.46^{* *}$ \\
\hline
\end{tabular}

Note: ${ }^{* *}$ Correlation is significant at the 0.01 level (two tailed); ${ }^{*}$ Correlation is significant at the 0.05 level (two tailed).

Table 4.

Stress induction.

\begin{tabular}{ccc}
\hline Speeded reactions to colours on the PC & Red & Blue \\
\hline Arrow keys for: high, low, left, right & Colors in squares & \\
Speeded reactions to tones coming via earphones & z to be pressed \\
Low tone & x to be pressed \\
High tone & \\
\hline
\end{tabular}


relation to respiration should be non-verbal. Even if decisions are required, like in our case, they should happen in silence. Pressing computer keys, as we used them as answers, would be a solution here. Given the relationship of stress and Minute volume a cross-validation is to be found in Wientjes (1993). In future research also the induction of stress could be evaluated, as probably not all respondents act according to the high-speed instruction.

We regard our results in spite of all rigorous controls still as preliminary, but a publication of them seems, according to our judgment, justified in order to allow repetitions or refutations. Perhaps one would come to different relationships with a different form of measuring defense mechanisms. This should be checked however empirically as well. The result that defense mechanisms have a moderating effect on stress is according to the hypothesis, that defenses, if they work, have an anxiety reducing influence. The inclusion of respiratory parameters adds also something to the validation of defense mechanisms, even if the results are mixed.

\section{References}

Bijleveld, C. C. J. H., \& Van der Burg, E. (1998). Analysis of longitudinal categorial data using optimal scaling techniques. In C. C. J. H. Bijleveld, L. J. H. Th. Van der Kamp et al. (Eds.), Longitudinal data analysis. Designs, models and methods (pp. 46-154). London: Sage.

Egle, U. T., Rudolf, M.-L., Hoffmann, S.O., König, K., Schöfer, M., Schwab, R., \& Wilmowsky, H. von (1989). Personality charachteristics, defensive behavior and illness experiences in patients with with primary fibromyalgy. Zeitschrift für Rheumatologie, 48, 73-78.

Geiser, F., Imbierovicz, K., Conrad, R., Wegener, I., \& Liedtke, R. (2005). Turning against self and its relation to symptom distress, interpersonal problems, and therapy outcome: A replicated and enhanced study. Psychotherapy Research, 15, 357-365. doi: $10.1080 / 10503300500226241$

Gleser, G., \& Ihilevich, D. (1969). An objective instrument for measuring defense mechanisms. Journal of Consulting and Clinical Psychology, 33, 51-60. doi:10.1037/h0027381

Harver, A., \& Lorig, T. S. (2000). Respiration. In J. T. Cacioppo, L. G. Tassinari and G. G. Berntson (Eds.), Handbook of psychophysiology (2nd ed.) (pp. 265-293). Cambridge: Cambridge University Press Hentschel, U., Kießling, M., \& Wiemers, M. (1998). Conflict-solving strategies inventory-FKBS. Weinheim: Beltz.

Hentschel, U., Smith, G., \& Draguns, J. G. (2004). Defense mechanisms and their psychophysiological correlates. In U. Hentschel, G. Smith, J. G. Draguns and W. Ehlers (Eds.), Defense mechanisms. Theoretical, research and clinical perspectives (pp. 611-633). Amsterdam: Elsevier. doi:10.1016/S0166-4115(04)80052-9

Hentschel, U., Van der Voort, M., \& Davids, A. (2007). On the evaluation of creativity in dream reports. In P. Herdina, A. Oberprantacher, \& J. Zelger (Eds.) Learning and development in organizations (pp. 260-279). Wien: Lit Verlag.

Hermann-Maurer, E. K., Drews, U., Imhof-Eichenberger, E., Knab, H., Schneider-Helmert, D., Hentschel, U., \& Schoenenberger, G. A. (1992). Sleep disturbances: Conflict solving strategies of patients suffering from insomnia. Zeitschrift für Klinische Psychologie, Psychopathologie und Psychotherapie, 40, 34-46.

Kragh, U. (1985). Defense mechanism Test-DMT manual. Stockholm: Persona.

Liedtke, R., Künsebeck, H.-W., \& Lempa, W. (1990). Changes in coping with conflicts during inpatient psychotherapy. Zeitschrift für Psychosomatische Medizin und Psychoanalyse, 36, 79-88.

Smith, G., \& Hentschel, U. (2004). Percept-genetic identification of defense. In U. Hentschel, G. Smith, J. G. Draguns, \& W. Ehlers (Eds.), Defense mechanisms. Theoretical, research and clinical perspectives (pp. 129-152). Amsterdam: Elsevier.

SPSS (1990). SPSS Categories. User's manual. Chicago, IL: SPSS Inc.

Van der Burg, E., De Leeuw, J., \& Verdegaal, R. (1988). Homogeneity analysis with k-sets of variables: An alternating least squares method with optimal scaling features. Psychometrika, 53, 177-197. doi: $10.1007 / \mathrm{BF} 02294131$

Van Praag, T. (1995). Respiratory movements and personality. Master;s Thesis, Leiden: Leiden University.

Vaillant, G. E. (1977). Adaptation to life. Boston, MA: Little, Brown \& Co.

Wientjes, C. J. E. (1993). Psychological influences upon breathing: Situational and dispositional aspects. Dissertation, Tilburg: University of Tilburg.

Wientjes, C. J. E., Grossman, P., Gaillard, A. W. K., \& Defares, P. B. (1986). Individual differences in respiration and stress. In R. Hockey, A. W. K. Gaillard and M. Coles (Eds.), Energetics and human information processing (pp. 317-327). Dordrecht: Nijhoff. 